\title{
Aromatase inhibitor-associated bone loss and its management with bisphosphonates in patients with breast cancer
}

This article was published in the following Dove Press journal:

Breast Cancer:Targets and Therapy

19 June 2012

Number of times this article has been viewed

\author{
M Bauer' \\ J Bryce ${ }^{2}$ \\ P Hadji ${ }^{1}$ \\ 'University of Marburg, Marburg, \\ Germany; ${ }^{2}$ National Cancer Institute, \\ Naples, Italy
}

\begin{abstract}
Postmenopausal women have an increased risk of osteopenia and osteoporosis due to loss of the bone-protective effects of estrogen. Disease-related processes may also contribute to the risk of bone loss in postmenopausal women with breast cancer. One of the most common and severe safety issues associated with cancer therapy for patients with breast cancer is bone loss and the associated increase in risk of fractures. This paper reviews the recent literature pertaining to aromatase inhibitor (AI)-associated bone loss, and discusses suggested management and preventative approaches that may help patients remain on therapy to derive maximum clinical benefit. A case study is presented to illustrate the discussion. We observed that AIs are in widespread use for women with hormone receptor-positive breast cancer and are now recommended as adjuvant therapy, either as primary therapy or sequential to tamoxifen, for postmenopausal women. AIs target the estrogen biosynthetic pathway and deprive tumor cells of the growth-promoting effects of estrogen, and AI therapies provide benefits to patients in terms of improved disease-free survival. However, there is a concern regarding the increased risk of bone loss with prolonged AI therapy, which can be managed in many cases with the use of bisphosphonates and other interventions (eg, calcium, vitamin D supplementation, exercise).
\end{abstract}

Keywords: aromatase inhibitors, bisphosphonates, bone loss, breast cancer, estrogen

\section{Introduction}

Aromatase inhibitors (AIs) are increasingly used as adjuvant endocrine therapy, in addition to tamoxifen, for postmenopausal women with hormone-sensitive breast cancer. ${ }^{1}$ The estrogen receptor is expressed in a large proportion of breast cancer tumors and has growth-promoting effects on tumor cells. ${ }^{2}$ In about two thirds of all cases, breast cancer tumors are estrogen-sensitive. ${ }^{3}$ Accordingly, many treatment strategies have focused on hormonal ablation, antagonism of estrogen receptor signaling, and suppression of estrogen synthesis. ${ }^{2}$

AIs prevent estrogen synthesis by inhibiting the aromatase enzyme, which is responsible for the conversion of androgens to estrogen. ${ }^{4}$ Adjuvant therapy with third-generation AIs is now an accepted standard for adjuvant endocrine treatment in addition to tamoxifen. ${ }^{5,6}$ Third-generation AIs include the nonsteroidal formulations, letrozole and anastrozole, and the steroidal formulation, exemestane. ${ }^{4,7}$ Nearly complete suppression of plasma estrogen levels has been demonstrated consistently with all thirdgeneration AIs. ${ }^{8-13}$ A greater degree of estrogen suppression has been demonstrated with letrozole when compared with anastrozole in a similar study. ${ }^{9}$ Greater suppression of each tissue estrogen fraction was observed with letrozole in blood plasma as well as in tumor tissues. ${ }^{9}$ The clinical significance of these differences remains uncertain. 
A recent update from the American Society of Clinical Oncology (ASCO) clinical practice guidelines re-emphasized the recommendation that AI therapy should be considered for all postmenopausal women with hormone receptor-positive (HR+) breast cancers. ${ }^{14}$ In addition, St Gallen international expert consensus guidelines also suggest that AIs should be a preferred initial adjuvant endocrine therapy. ${ }^{15}$ Nowadays, AIs are used routinely in three different postsurgical treatment approaches for patients with breast cancer, ie, upfront monotherapy ( 5 years of initial treatment with an $\mathrm{AI}$ ), sequential adjuvant therapy (tamoxifen followed by an AI for a total of 5 years), and the extended adjuvant setting (using an AI after 5 years of tamoxifen). ${ }^{6}$ If an extended strategy is used, the ASCO guidelines update recommends 5 years of tamoxifen followed by $3-5$ years of an AI. ${ }^{14}$ Superior clinical efficacy has been shown with all AIs compared with tamoxifen alone in each of these settings. ${ }^{16-23}$ While there is clear evidence that inclusion of an AI in the treatment strategy, whether upfront or switching after tamoxifen, is superior to 5 years of tamoxifen alone, the optimal strategy for AI use remains unclear. ${ }^{24}$ However, only upfront use of an AI addresses the early peak of recurrence.

Following breast cancer surgery, there is a long-term risk of recurrence. ${ }^{25}$ The first peak of recurrence occurs 1-2 years postsurgery. ${ }^{25}$ The most common type of recurrence seen during this early peak is distant metastasis, while locoregional and contralateral recurrences occur at a much lower rate. ${ }^{26}$ This is important because distant metastasis is associated with increased mortality. ${ }^{27}$ Therefore, therapies that reduce distant metastasis during this early peak of recurrence may have the potential to improve survival. ${ }^{27}$

All AI therapies, both as initial and as sequential therapy, have improved disease-free survival in patients with breast cancer; however, the effect on distant metastasis has not been uniform among AIs. ${ }^{16-19,21,22,28-32}$ The Breast International Group (BIG) 1-98 Arimidex, Tamoxifen Alone or in Combination (ATAC) and Tamoxifen Exemestane Adjuvant Multinational (TEAM) trials examined initial AI therapy compared with tamoxifen. The BIG 1-98 trial investigated the following adjuvant treatments in HR+ postmenopausal women following breast surgery: upfront initial letrozole for 5 years, upfront initial tamoxifen for 5 years, 2 years of letrozole followed by 3 years of tamoxifen, or 2 years of tamoxifen followed by 3 years of letrozole. ${ }^{17}$ The initial results of the BIG 1-98 trial $(\mathrm{n}=8010)$ at a median follow-up of 25.8 months demonstrated the superiority of letrozole over tamoxifen in significantly prolonging disease-free survival (hazard ratio $[\mathrm{HR}]=0.81 ; P=0.003) .{ }^{17}$ In addition, letrozole-treated patients had a significant $(P=0.001)$ early benefit in time to distant recurrence, with a $27 \%$ reduction in risk of distant metastasis at this early time point. ${ }^{17}$ Based on the results demonstrating the superiority of letrozole, the tamoxifen monotherapy arm was unblinded and patients were permitted to cross over to letrozole. The significant benefits of letrozole on disease-free survival ( $\mathrm{HR}=0.88 ; P=0.03$ ) and distant metastasis $(\mathrm{HR}=0.85 ; P=0.05)$ were maintained at a median follow-up of 76 months (monotherapy arms, $\mathrm{n}=4922$ ), despite crossover of $25.2 \%$ of patients. ${ }^{19}$ In addition, there was a trend (HR $=0.87 ; P=0.08)$ in the intent-totreat population suggesting an overall survival benefit with letrozole. Because the crossover complicated the results, the inverse probability of a censored weighting method was utilized. Using this method, a 17\% (95\% confidence interval [CI], 0.71-0.97) improvement in overall survival was seen with letrozole compared with tamoxifen. Similar to the BIG 1-98 trial, the ATAC trial $(\mathrm{N}=9366$ overall; $\mathrm{n}=5216$ $\mathrm{HR}+$ patients), which compared anastrozole with tamoxifen monotherapy in HR+ and HR-unknown postmenopausal women following breast cancer surgery, demonstrated a significant $(\mathrm{HR}=0.83 ; P=0.005)$ disease-free survival benefit with anastrozole over tamoxifen at 68 months' median follow-up in HR+ patients..$^{16}$ However, anastrozole did not provide a significant $(\mathrm{HR}=0.84 ; P=0.06)$ reduction in distant metastasis at this time point, nor was there any overall survival benefit $(\mathrm{HR}=0.97 ; P=0.7)$. Only at 100 months' follow-up was there a significant $(\mathrm{HR}=0.84$; $P=0.022)$ distant metastasis benefit, along with maintenance of a significant benefit in disease-free survival $(\mathrm{HR}=0.85$; $P=0.003)$, but there was still no overall survival improvement (HR $=0.97 ; P=0.7) .{ }^{31}$ The TEAM trial $(\mathrm{n}=9766)$ was originally designed to compare adjuvant therapy with 5 years of exemestane versus 5 years of tamoxifen in postmenopausal women with HR+ breast cancer. ${ }^{23}$ However, it was modified to include sequential therapy with tamoxifen for $2.5-3.0$ years followed by exemestane. The first coprimary endpoint at 2.75 years analyzed patients randomized to initial therapy with exemestane or tamoxifen, and found no significant improvement in disease-free survival with exemestane compared with tamoxifen ( $\mathrm{HR}=0.89 ; P=0.12$ ). The second coprimary endpoint at 5 years, comparing exemestane monotherapy versus sequential therapy (tamoxifen to exemestane), also showed no difference in disease-free survival $(\mathrm{HR}=0.97$; $P=0.604) .{ }^{33}$

Switch studies differ from initial adjuvant trials in that patients are randomized after completing 2-3 years of tamoxifen, and they exclude patients with disease recurrence 
(including patients with early distant metastases) during this prerandomization period. The Intergroup Exemestane Study (IES) examined estrogen receptor-positive $(E R+)$ or ER-unknown patients $(n=4742)$ receiving tamoxifen followed by exemestane versus patients receiving tamoxifen monotherapy. ${ }^{22}$ In hormone-responsive patients at a median follow-up of 56 months, the IES showed a significant improvement in disease-free survival in patients who switched to exemestane after 2-3 years of tamoxifen treatment $(\mathrm{HR}=0.75 ; P=0.0001) .{ }^{22}$ The results of this study also demonstrated significant improvement in overall survival in this patient population ( $\mathrm{HR}=0.83 ; P=0.05)$. The Austrian Breast and Colorectal Cancer Study Group (ABCSG) 8 trial compared tamoxifen followed by anastrozole versus tamoxifen monotherapy in hormone-sensitive patients with breast cancer $\left(\mathrm{n}=2566\right.$ switch population).$^{30}$ At 30 months' median follow-up, event-free survival favored sequential therapy $(\mathrm{HR}=0.68 ; P=0.02)$. However, switch trials do not include distant metastasis occurring during the early periods following surgery and only examine patients who respond to therapy. Initial adjuvant AI therapy has demonstrated superior efficacy compared with tamoxifen, but only letrozole significantly reduced early distant metastasis, possibly resulting in a long-term survival advantage.

Even though AI therapy has clear benefits for patients with breast cancer, AIs can also have detrimental long-term effects on bone health. ${ }^{34-36}$ Bone loss is a predictable consequence of estrogen deprivation. ${ }^{37}$ Estrogen has a negative regulatory effect on bone resorption; therefore, any therapy that depletes estrogen has the potential to cause bone loss, impacting bone integrity and putting the patient at risk for fractures. Postmenopausal patients with breast cancer are already at an increased risk of osteoporosis due to agerelated failure of ovarian function, a corresponding decline in estrogen levels, and possible disease-related bone loss. Potential treatment-related bone loss may be an added risk factor. ${ }^{2,38-40}$ Cancer treatment-induced bone loss may be accentuated in women with breast cancer who are receiving multiple forms of anticancer treatment (eg, chemotherapy, endocrine therapy). ${ }^{41}$

For example, average lumbar spine bone mineral loss at one year has been reported to be $1 \%-2 \%$ in early and late menopausal women, compared with $7.7 \%$ in women with ovarian failure secondary to chemotherapy (Figure 1). AI-induced bone loss with endocrine therapy is associated with rapid bone loss and an increased fracture risk that is distinctly different from that observed in postmenopausal osteoporosis (Figure 1). ${ }^{2}$ One of the most common side effects of AI use is skeletal bone loss leading to thinning of the bone (osteopenia) and/or an increased risk of bone fractures. ${ }^{6,42,43}$ When combined with other treatments, this risk may be significantly enhanced (Figure 1). Eastell et al reported a $2.6 \%$ loss in lumbar spine bone mineral density in postmenopausal women with breast cancer receiving AI treatment. ${ }^{44}$ In comparison, a $7 \%$ loss was reported in women receiving AI therapy combined with a gonadotropin-releasing hormone agonist. ${ }^{45}$

The bone loss seen during AI treatment appears to be similar from one agent to another within this class, although there is a paucity of data from direct comparator trials..$^{21,46}$ A randomized investigation of healthy volunteers (Letrozole, Exemestane, and Anastrozole Pharmacodynamic trial) demonstrated that all AIs (steroidal or nonsteroidal) have a similar effect on bone and are associated with increased bone turnover. ${ }^{47}$ Recently, there has been greater recognition of the increased fracture rates and bone loss seen in studies of patients undergoing AI therapy, ${ }^{48,49}$ and also of the need for appropriate management and intervention to reduce bone loss and prevent fragility fractures. ${ }^{34,42,50,51}$ This paper reviews the recent literature pertaining to the risk of fractures and the premature or accelerated development of bone loss in patients treated with adjuvant AI therapy. A case study is described for a patient who demonstrated decreasing bone mineral density while undergoing treatment with endocrine therapy. Suggested management approaches are also discussed.

\section{Al-associated bone loss}

Bone tissue undergoes a continuous resorption/formation process. Small amounts of bone mineral that are removed by osteoclasts (resorption) are balanced by equal deposition of new mineral by osteoblasts (formation), preserving bone strength. ${ }^{52}$ Estrogen is one of the crucial modulators of bone formation. In postmenopausal women, low estrogen levels are associated with increased bone turnover, which may result in

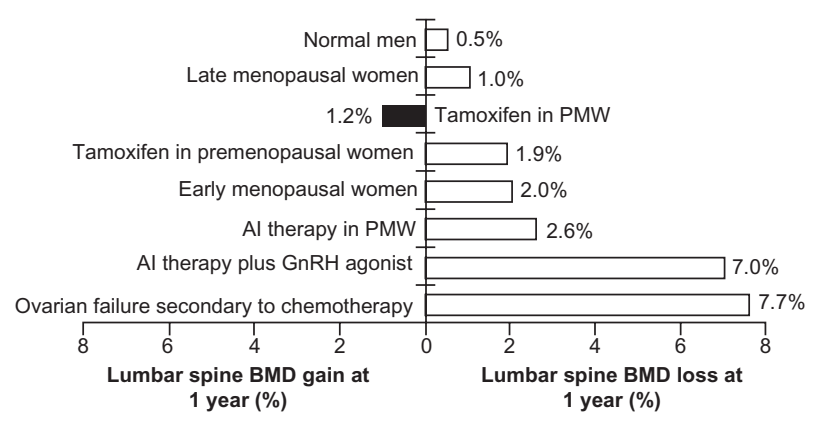

Figure I Cancer treatment-induced bone loss. ${ }^{44,45,88-90}$

Abbreviations: $\mathrm{Al}$, aromatase inhibitor; BMD, bone mineral density; $\mathrm{GnRH}$, gonadotropin-releasing hormone; PMW, postmenopausal women. 
net bone loss, ${ }^{53-55}$ a decrease in bone strength, and an increased fracture risk. ${ }^{37,55-58}$ Adjuvant endocrine therapy is designed to deprive tumor cells of the growth-promoting effects of estrogen. ${ }^{59}$ AIs prevent estrogen synthesis by inhibiting the aromatase enzyme, which is responsible for the conversion of androgens to estrogen. ${ }^{4}$ Therefore, estrogen deprivation during AI therapy in postmenopausal women may increase bone turnover and induce bone loss, which is observed at sites rich in trabecular bone, at an average rate of 1\%-3\% annually. This leads to an increase in fracture incidence compared with that seen during tamoxifen therapy. ${ }^{60}$ Although the mechanism of action between the steroidal (binding irreversibly to aromatase, eg, exemestane) and nonsteroidal (competitive inhibitors that bind to the heme moiety of the aromatase cytochrome P450 complex, eg, anastrozole, letrozole) ${ }^{61}$ AIs is somewhat different, adverse effects on bone health have been observed with all currently used AIs (Table 1).

\section{Anastrozole}

The ATAC trial compared the efficacy and safety of anastrozole with that of tamoxifen in the initial adjuvant setting in postmenopausal women with early breast cancer. ${ }^{16,28}$ After a median follow-up of 68 months, the fracture rate was $11 \%$ for patients treated with anastrozole $(n=3092)$ versus $7.7 \%$ in patients treated with tamoxifen $(n=3094) .{ }^{16}$

\section{Letrozole}

The BIG 1-98 trial is the largest ongoing trial comparing letrozole with tamoxifen in the initial adjuvant setting. A slight but significant $(P<0.001)$ difference in fracture rate was observed between the letrozole arm (5.7\%) and the tamoxifen arm (4.0\%) at 25.8 months of median follow-up. ${ }^{17}$ At 51 months of follow-up, letrozole $(n=2448)$ was associated with an $8.6 \%$ versus $5.8 \%$ fracture rate with tamoxifen
$(\mathrm{n}=2447)(P<0.001) .{ }^{18}$ At 5 years of follow-up, the incidence of bone fractures remained higher among patients treated with letrozole $(9.3 \%$ versus tamoxifen $6.5 \%$; no $P$ value reported). ${ }^{62}$ The wrist was found to be the most common site of fracture in each treatment group.

\section{Exemestane}

In the IES, patients were randomized to either 5 years of tamoxifen $(n=2372)$ or a switch to exemestane following 2-3 years of tamoxifen treatment $(n=2352)$ for a total of 5 years. Within 6 months of switching to exemestane, bone mineral density was lowered by $2.7 \%$ at the lumbar spine and $1.4 \%$ at the hip compared with baseline values $(P<0.0001$ at both sites). ${ }^{63}$ All in all, 162 patients (7\%) in the exemestane arm and $115(5 \%)$ in the tamoxifen arm had fractures at a mean follow-up of 58 months $(P=0.01)$. In the TEAM trial, tamoxifen treatment resulted in a $0.5 \%$ increase from baseline in bone mineral density at the spine, which was maintained at the 12-month assessment $(n=83)$. In contrast, exemestane treatment resulted in an increase in bone loss at 6 months $(2.6 \%$ decrease in spine bone mineral density) and a further decrease of $0.2 \%$ at 12 months $(n=78) .{ }^{36}$ In a recent subanalysis of the TEAM trial, exemestane resulted in increases from baseline in all bone turnover markers (eg, bone-specific alkaline phosphatase, amino terminal propeptide type I, procollagen, osteocalcin) at all time points. ${ }^{64}$ In contrast, levels of all bone turnover markers decreased with tamoxifen treatment.

\section{Case report}

A 62-year-old postmenopausal female presented with ER+, progesterone receptor-positive, human epidermal growth factor receptor 2-negative breast cancer. The patient's age of menopausal onset was 51 years and she received hormone

Table I Bone-related and fracture-related adverse events from aromatase inhibitor (Al) trials 5 , 18,22,31,62

\begin{tabular}{|c|c|c|c|c|c|c|}
\hline $\begin{array}{l}\text { Trial } \\
\text { (follow-up) }\end{array}$ & $\begin{array}{l}\text { Adjuvant therapy } \\
\text { type }\end{array}$ & Al & Comparator & $\begin{array}{l}\text { Definition of } \\
\text { adverse event }\end{array}$ & $\begin{array}{l}\text { Al versus } \\
\text { comparator }\end{array}$ & $P$ value \\
\hline $\begin{array}{l}\text { ATAC } \\
\text { (68 months) }\end{array}$ & Initial adjuvant & ANA & TAM & $\begin{array}{l}\text { Overall fracture rate } \\
\text { Osteopenia or } \\
\text { osteoporosis }\end{array}$ & $\begin{array}{l}\text { II.0\% versus } 7.7 \% \\
\text { II.0\% versus } 7.0 \%\end{array}$ & $\begin{array}{l}<0.0001 \\
<0.0001\end{array}$ \\
\hline $\begin{array}{l}\text { BIG I-98 } \\
\text { (60.3 months) }\end{array}$ & Initial adjuvant & LET & TAM & Overall fracture rate & $9.3 \%$ versus $6.5 \%$ & $<0.001$ \\
\hline $\begin{array}{l}\text { IES } \\
\text { (55.7 months) }\end{array}$ & Switch adjuvant & EXE & TAM & $\begin{array}{l}\text { Overall fracture rate } \\
\text { Osteoporosis }\end{array}$ & $\begin{array}{l}7.0 \% \text { versus } 4.9 \% \\
9.2 \% \text { versus } 7.2 \%\end{array}$ & $\begin{array}{l}0.003 \\
0.01\end{array}$ \\
\hline $\begin{array}{l}\text { TEAM } \\
\text { (32 months) }\end{array}$ & Initial adjuvant & EXE & TAM & $\begin{array}{l}\text { Overall fracture rate } \\
\text { Osteoporosis }\end{array}$ & $\begin{array}{l}2.7 \% \text { versus } 2.3 \% \\
4.7 \% \text { versus } 2.1 \%\end{array}$ & $\begin{array}{l}\text { NS } \\
\leq 0.001\end{array}$ \\
\hline
\end{tabular}

(c) 2010 Reprinted with permission from Elsevier. Janni W, Hepp P. Adjuvant aromatase inhibitor therapy: Outcomes and safety. Cancer Treat Rev. 20I0;36:249-26I. ${ }^{5}$ Abbreviations: ANA, anastrozole; ATAC, Arimidex Tamoxifen Alone or in Combination; BIG, Breast International Group; EXE, exemestane; IES, Intergroup Exemestane Study; LET, letrozole; NR, not reported; NS, not significant; TAM, tamoxifen; TEAM, Tamoxifen, Exemestane Adjuvant Multicenter. 
replacement therapy until her diagnosis of breast cancer. She did not have any family history relevant to osteoporosis, and there was no history of prevalent fractures, glucocorticoid therapy, chemotherapy, or smoking.

The patient was diagnosed to have invasive ductal breast cancer on the left side. Upon diagnosis, she underwent the standard procedure in Germany which included chest radiography, liver ultrasound, and scintigraphy, and all tests revealed no sign of metastasis. Breast-conserving surgery (including sentinel lymphadenectomy) was performed. One month later, skeleton scintigraphy showed no sign of bone metastasis and the patient was placed on AI therapy (letrozole $2.5 \mathrm{mg}$ /day, orally). The patient also received adjuvant radiation therapy to the left breast. Her bone mineral density was measured by dual-energy x-ray absorptiometry at two locations, ie, the femur and lumbar spine (initial, 12-month, and 24-month data are presented in Figures 2-4 [A, B, and $C$, respectively] and Table 2). Quantitative ultrasound assessments of bone were also made at the initial, 12, and 24-month time points (Table 2). The patient's bone scans showed decreasing bone mineral density over time while on letrozole treatment.

\section{Guidelines for bone loss management}

Osteoporosis screening and treatment are standard components of health maintenance in postmenopausal women; however, current treatment and preventative guidelines are inadequate for averting fractures in osteopenic women with breast cancer, especially those receiving AI therapy. ${ }^{65,66}$ A more complete understanding of clinically relevant risk factors for fracture will help to assess overall fracture risk and provide practical guidance for the prevention and treatment of bone loss in this population. ${ }^{34,65,66}$

In order to place bone mineral density assessments and other risk factors within the context of identifying women with breast cancer who are at increased risk of fracture, and who are likely candidates for preventative therapy, a panel of experts recently evaluated data from large clinical trials in postmenopausal women and women with breast cancer to develop international consensus guidelines for using clinical risk factors for fracture along with bone mineral density measurements. ${ }^{67}$ Eight risk factors were validated in women with breast cancer, including AI therapy, $\mathrm{t}$ score $<-1.5$, age $>65$ years, low body mass index $\left(<20 \mathrm{~kg} / \mathrm{m}^{2}\right)$, family history of hip fracture, personal history of fragility fracture after the age of 50 years, oral corticosteroid use $>6$ months, and smoking. ${ }^{34,68}$ These current guidelines underscore the importance of comprehensive fracture risk assessment and advocate bone mineral density measurement in all patients taking AIs with selective use of antiresorptive therapy in osteoporotic (t score $<-2.5$ ) women. ${ }^{68,69}$ Evaluating both bone mineral density and clinical risk factors may allow for the most effective identification of patients with breast
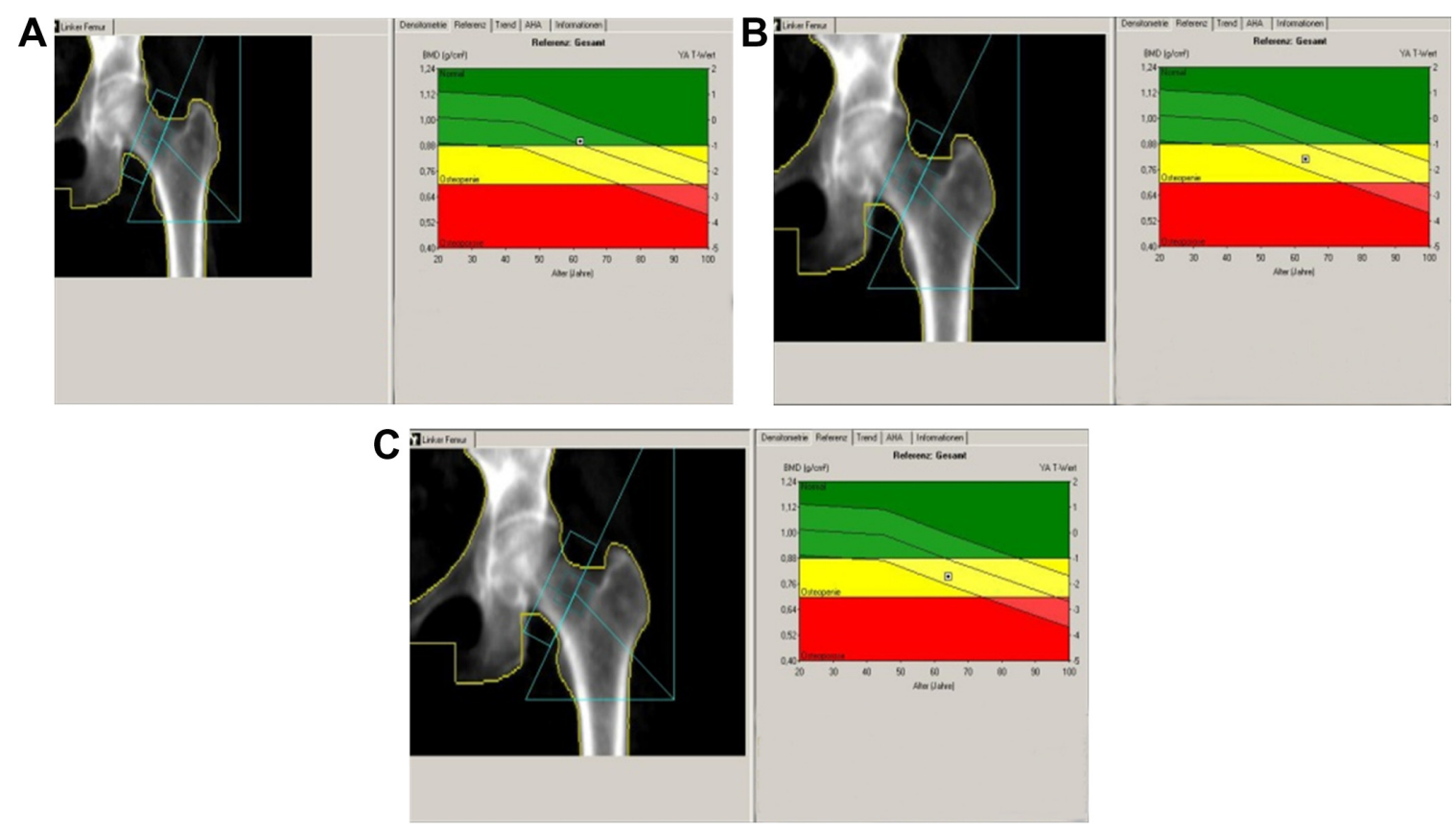

Figure 2 Left femur bone mass density over time. (A) At baseline, (B) at 12 months, and (C) at 24 months. Note: Bone scans provided by authors. 

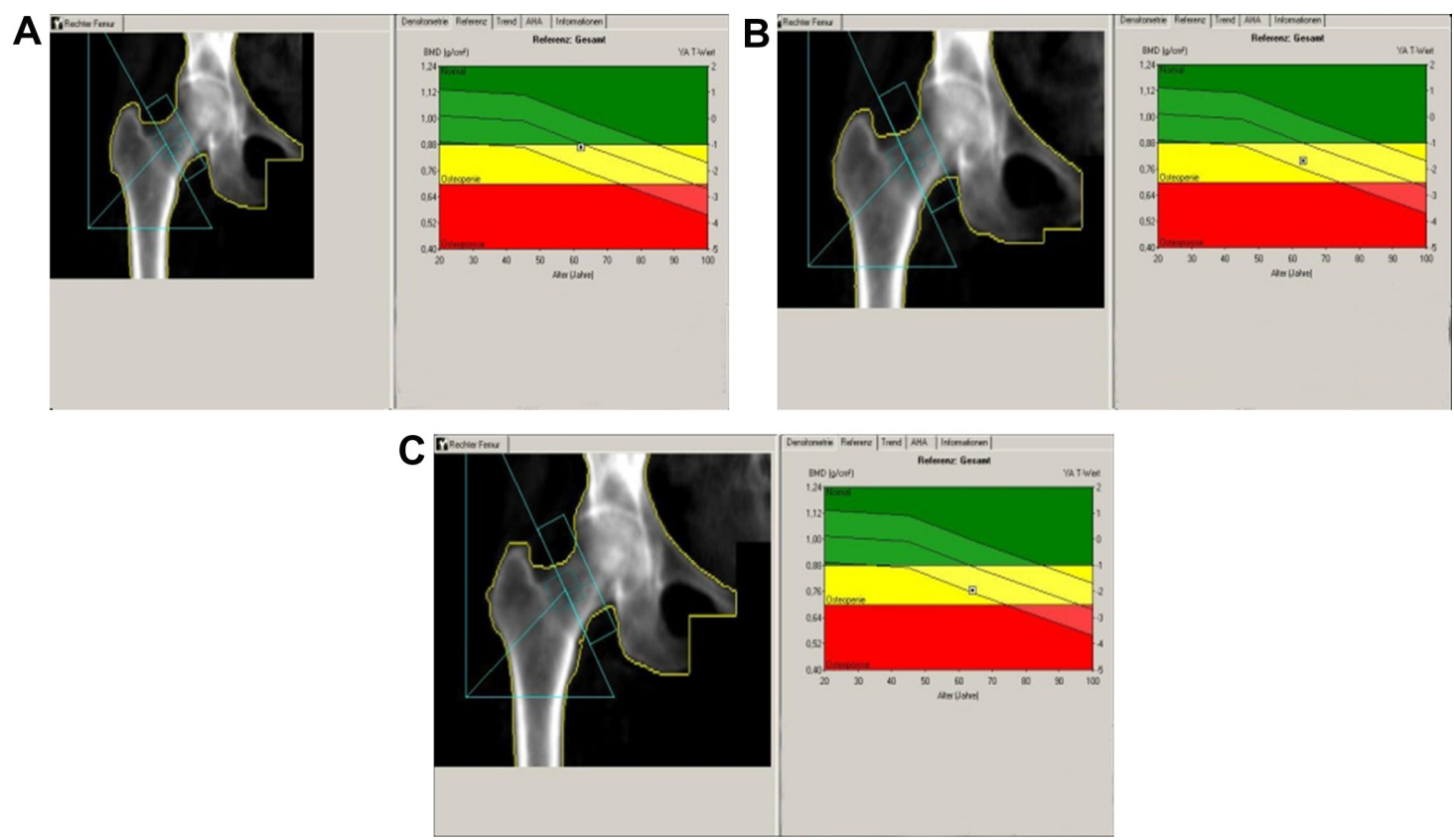

Figure 3 Right femur bone mass density over time. (A) At baseline, (B) at 12 months, and (C) at 24 months. Note: Bone scans provided by authors.

cancer who have an increased risk of fracture as well as the appropriate use of preventative therapies. ${ }^{70}$

\section{Zometa-Femara Adjuvant Synergy Trials}

Mounting evidence now suggests that treatment with bisphosphonates (eg, zoledronic acid) may help manage and potentially prevent $\mathrm{AI}$-associated bone loss. ${ }^{2,24,50,68,71,72}$ Because of the increased bone loss associated with use of AIs, three randomized international studies, ie, the ZometaFemara Adjuvant Synergy Trials (Z-FAST, ZO-FAST, and E-ZO-FAST), were performed to evaluate the boneprotective effects of zoledronic acid during endocrine treatment with letrozole. The primary endpoint of these
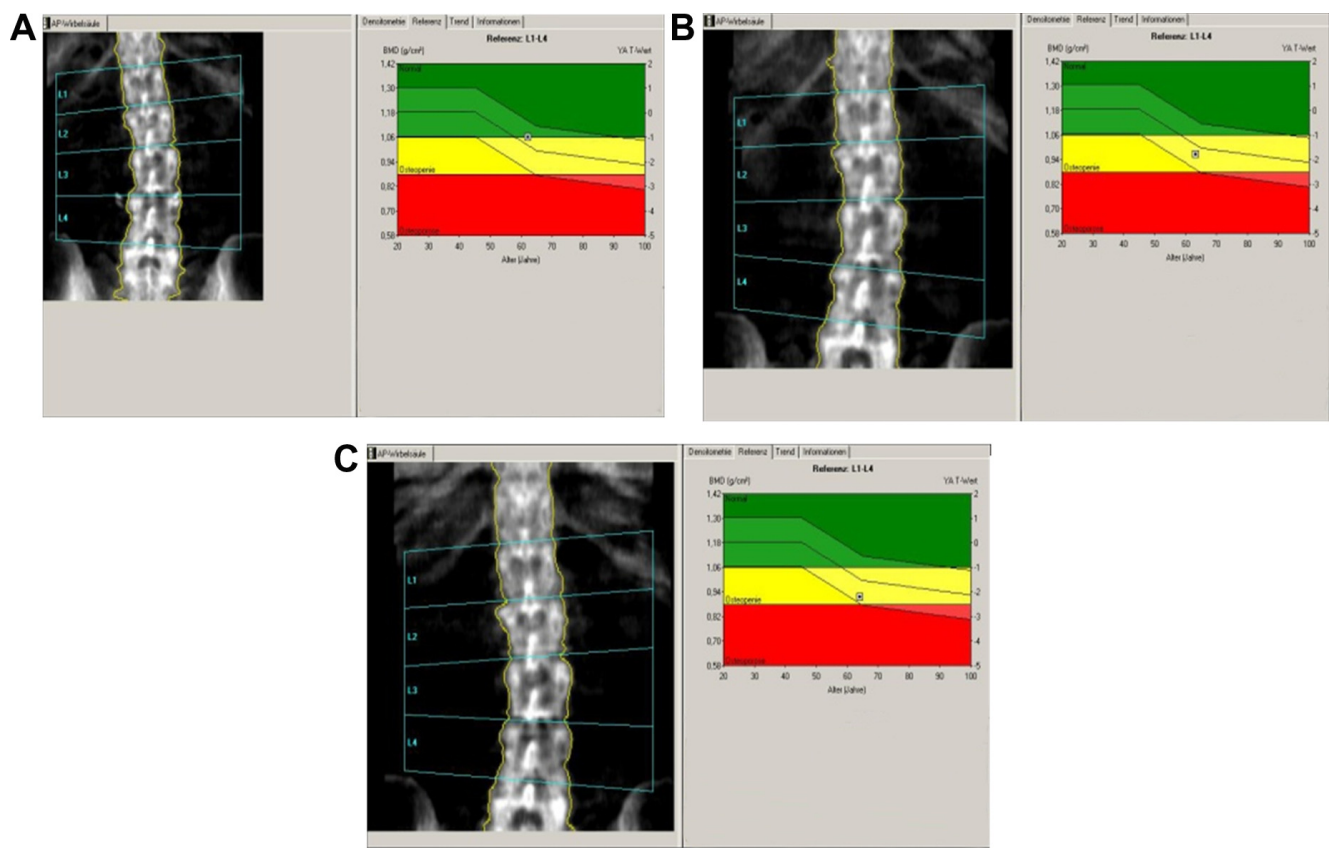

Figure 4 Lumbar spine bone mass density over time. (A) At baseline, (B) at 12 months, and (C) at 24 months. 
Table 2 Dual-energy X-ray absorptiometry (DXA) and quantitative ultrasound (QUS) results

\begin{tabular}{|c|c|c|}
\hline DXA LS baseline & DXA femur baseline & QUS baseline \\
\hline BMD LI-L4: I.059 & Right/left & Right/left \\
\hline \multirow[t]{4}{*}{ T score LI-L4: -1.0} & Neck BMD 0.826/0.79I & T score $-0.6 /-1.8$ \\
\hline & Neck t score $-1.3 /-1.6$ & Stiffness index \\
\hline & Neck total BMD 0.867/0.899 & $92 / 77$ \\
\hline & Neck total t score $-1.1 /-0.8$ & \\
\hline DXA LS I 2 months & DXA femur 12 months & QUS 12 months \\
\hline BMD LI-L4: 0.965 & Right/left & Right/left \\
\hline \multirow[t]{4}{*}{ T score LI-L4: -I.8 } & Neck BMD 0.778/0.767 & T score $-2.2 /-3.3$ \\
\hline & Neck t score - I.7/-1.8 & Stiffness index \\
\hline & Neck total BMD 0.796/0.809 & $72 / 58$ \\
\hline & Neck total t score $-1.7 /-1.6$ & \\
\hline DXA LS 2 years & DXA femur 24 months & QUS 24 months \\
\hline BMD LI-L4: I.916 & Right/left & Right/left \\
\hline \multirow[t]{4}{*}{ T score LI-L4: -2.2} & Neck BMD 0.733/0.749 & T score $-1.3 /-3.1$ \\
\hline & Neck t score $-2.1 /-1.9$ & Stiffness index \\
\hline & Neck total BMD 0.764/0.792 & $84 / 59$ \\
\hline & Neck total t score $-2.0 /-1.7$ & \\
\hline
\end{tabular}

Abbreviations: BMD, bone mineral density; LS, lumbar spine.

companion trials was to determine the impact of upfront or delayed (if $\mathrm{t}$ score $<-2.0$ or in the presence of a fracture) zoledronic acid on bone mineral density at the lumbar spine at 12 months in postmenopausal women $(\mathrm{n}=2194)$ with hormone-sensitive breast cancer receiving letrozole. Secondary endpoints included fracture rate, disease-free survival, and disease recurrence. These studies have all shown that the bone mineral density loss associated with AI therapy can be prevented effectively by adjuvant treatment with zoledronic acid. Current management guidelines now recommend that any patient initiating or receiving AI therapy with any two identified risk factors should receive bisphosphonate therapy. ${ }^{34}$

The results of the Z-FAST study demonstrate a continuous annual bone mineral density increase at both the lumbar spine and total hip in patients who were receiving upfront zoledronic acid $(\mathrm{n}=301)$ versus delayed treatment $(\mathrm{n}=301) .{ }^{72}$ Long-term 5 -year follow-up data confirm that compared with a delayed start, upfront zoledronic acid (4 mg intravenously every 6 months) effectively prevents/treats bone loss in postmenopausal women, regardless of baseline $\mathrm{t}$ score, chemotherapy status, or number of osteoporotic risk factors. ${ }^{72}$ The results show a progressive and significantly increased lumbar spine and total hip bone mineral density over 5 years with upfront zoledronic acid treatment (percent change in lumbar spine and total hip bone mineral density from baseline at 61 months: $6.19 \%$ and $2.57 \%$, respectively, $P<0.0001) .{ }^{72}$ Similarly, in the ZO-FAST study $(\mathrm{n}=1065)$, there were significant increases in bone mineral density in favor of upfront zoledronic acid compared with delayed zoledronic acid at the 5-year final follow-up (lumbar spine $10 \%, P<0.0001) .{ }^{73}$ However, it should be noted that there was no difference observed in fracture rates between the two treatment groups (upfront or delayed). ${ }^{73}$ Over the 5 -year study duration, osteonecrosis of the jaw was found in $4 / 669$ patients who received zoledronic acid $(0.6 \%) .{ }^{73}$ Other adverse events were consistent with the known safety profile of zoledronic acid.

\section{Potential anticancer activity of bisphosphonates}

The principal biologic effect of bisphosphonates is to inhibit osteoclastic bone resorption; these agents may impede both the development of bone metastases and the survival of dormant cancer cells in the bone marrow microenvironment. ${ }^{74-76}$ In addition to their primary effect upon bone mineral density, bisphosphonates also may confer additional anticancer benefits. Several direct and indirect mechanisms may contribute to this anticancer activity, including cancer cell apoptosis, inhibition of proliferation and migration, reduction in angiogenesis, activation of the immune system against cancer cells, and synergistic effects with other cancer treatments such as endocrine and chemotherapies. ${ }^{76,77}$ Therefore, bisphosphonates may provide further clinical benefit to patients with breast cancer by reducing the risk of distant and bone metastasis and increasing overall survival and disease-free survival. ${ }^{78}$

Given the potential anticancer activity of the bisphosphonates, the Zometa-Femara Adjuvant Synergy Trials included disease-free survival as a secondary endpoint, although the studies were insufficiently powered to detect differences between treatment arms for this variable, and the findings should be interpreted with caution (Table 3 ). In the recent analysis at 5-year follow-up of the ZO-FAST study, upfront zoledronic acid was associated with a significant $34 \%$ reduction in risk of recurrence compared with use of delayed zoledronic acid $(P=0.034) .{ }^{73,79}$ However, recently published data from the AZURE trial that examined adjuvant use of bisphosphonates in reducing rates of recurrence and death in patients with early-stage breast cancer found no significant between-group difference in disease-free survival (primary endpoint of this study) in patients on standard adjuvant systemic therapy either with or without zoledronic acid. ${ }^{80}$

\section{Discussion}

Use of emerging international guidelines to initiate bisphosphonate therapy as an early intervention strategy may 
Table 3 Disease-free survival (DFS) events and deaths ${ }^{\mathrm{a}}$

\begin{tabular}{|c|c|c|c|c|c|c|}
\hline \multirow{3}{*}{$\begin{array}{l}\text { Median follow-up, } \\
\text { months }\end{array}$} & \multicolumn{2}{|c|}{ ZO-FAST $^{81}$} & \multicolumn{2}{|l|}{ Z-FAST ${ }^{72}$} & \multicolumn{2}{|c|}{ E-ZO-FAST $^{81}$} \\
\hline & \multicolumn{2}{|l|}{48} & \multicolumn{2}{|l|}{61} & \multicolumn{2}{|l|}{36} \\
\hline & $\begin{array}{l}\text { Upfront } \\
(n=532)\end{array}$ & $\begin{array}{l}\text { Delayed } \\
(n=533)\end{array}$ & $\begin{array}{l}\text { Upfront } \\
(n=30 I)\end{array}$ & $\begin{array}{l}\text { Delayed } \\
(n=30 I)\end{array}$ & $\begin{array}{l}\text { Upfront } \\
(n=263)\end{array}$ & $\begin{array}{l}\text { Delayed } \\
(n=264)\end{array}$ \\
\hline DFS events & 32 & 53 & - & - & 19 & 11 \\
\hline $\begin{array}{l}\text { Patients with disease } \\
\text { recurrence for Z-FAST (n) }\end{array}$ & - & - & 16 & 21 & - & - \\
\hline Deaths (any cause) & 16 & 26 & 7 & 4 & 9 & 2 \\
\hline
\end{tabular}

Note: ${ }^{Z}$-FAST, ZO-FAST, and E-ZO-FAST are studies in the series of the Zometa-Femara Adjuvant Synergy Trials.

help to prevent a large percentage of all potential fractures in postmenopausal patients with breast cancer receiving AI therapy. ${ }^{34,70}$ The case study discussed herein represents one potential illustrative example. The patient concerned would not have been eligible for zoledronic acid treatment based on her scans at 12 months because the $t$ score was more than -2 and there was an absence of other risk factors, eg, family history. Nevertheless, extended treatment with letrozole and the latest scan in 2009 demonstrated that the patient would be a potential candidate for zoledronic acid treatment.

Given its significant benefit in breast cancer treatment, eg, reduction in distant metastases, AI therapy should be maintained with effective management of adverse events in order to maximize patient benefit. The benefits of superior disease control should always be considered along with effective management of adverse events. Effective management of bone loss with adjuvant bisphosphonate therapy has been demonstrated while maintaining AI therapy. ${ }^{81}$ The bone mineral density loss seen in the patient described in the present case report may have been mitigated with early intervention with adjuvant zoledronic acid therapy. Other strategies may also be combined with bisphosphonate therapy for the effective management of AI-associated bone loss. These strategies may include various lifestyle adjustments, such as muscle-strengthening exercises, reduced alcohol consumption, cessation of smoking, and dietary supplementation with calcium and vitamin $\mathrm{D}^{82-86}$

\section{Conclusion}

Adjuvant AI treatment of HR+ breast cancer in postmenopausal women has now become the standard of care due to superior disease-free survival results and a more favorable side effect profile compared with tamoxifen. However, due to the profound estrogen depletion that occurs with AI therapy, negative effects on bone health may also be observed. Screening and medical management for bone complications in patients with breast cancer being treated with AIs is therefore an important area for clinical intervention. The presence of risk factors (eg, age, $\mathrm{t}$ score, body mass index, family and personal history, smoking) may be used for appropriate patient stratification and determination of an optimal treatment plan to preserve bone integrity. Several studies have demonstrated the efficacy of antiresorptive agents (eg, bisphosphonates) for prevention of the bone mineral density loss associated with breast cancer therapy. Although no treatments are approved specifically for AI-associated bone loss, patients at high risk of rapid bone loss may benefit from early and sustained intravenous bisphosphonate therapy. Adequate calcium and vitamin D supplementation and a healthy lifestyle may also positively impact long-term bone health. In the case study presented herein, eligibility for bisphosphonate therapy according to the 2006 consensus guidelines would not have been met due to the lack of risk factors and bone mineral density being above the guideline threshold values. However, according to the revised 2009 guidelines, eligibility criteria would have been met. In addition to the positive effects on bone health, there is now some evidence supporting the potential anticancer benefits of bisphosphonate therapy. Therefore, patients may potentially derive dual benefit from both improvement in bone health and anticancer activity.

\section{Disclosure}

Financial support for the medical editorial assistance of Maria Soushko was provided by Novartis Pharmaceuticals.

\section{References}

1. Mortimer JE. Managing the toxicities of the aromatase inhibitors. Curr Opin Obstet Gynecol. 2010;22:56-60.

2. Hadji P. Aromatase inhibitor-associated bone loss in breast cancer patients is distinct from postmenopausal osteoporosis. Crit Rev Oncol Hematol. 2009;69:73-82.

3. Folkestad L, Bjarnason NH, Bjerregaard JK, Brixen K. The effect of aromatase inhibitors on bone metabolism. Basic Clin Pharmacol Toxicol. 2008;104:3-10. 
4. Miller WR, Bartlett J, Brodie AM, et al. Aromatase inhibitors: are there differences between steroidal and nonsteroidal aromatase inhibitors and do they matter? Oncologist. 2008;13:829-837.

5. Janni W, Hepp P. Adjuvant aromatase inhibitor therapy: outcomes and safety. Cancer Treat Rev. 2010;36:249-261.

6. Conte P, Frassoldati A. Aromatase inhibitors in the adjuvant treatment of postmenopausal women with early breast cancer: putting safety into perspective. Breast J. 2007;13:28-35.

7. Ozair S, Iqbal S. Efficacy and safety of aromatase inhibitors in early breast cancer. Expert Opin Drug Saf. 2008;7:547-558.

8. Macedo LF, Sabnis G, Brodie A. Aromatase inhibitors and breast cancer. Ann N Y Acad Sci. 2009;1155:162-173.

9. Geisler J. Aromatase inhibitors: from bench to bedside and back. Breast Cancer. 2008; 15:17-26.

10. Geisler J, King N, Dowsett M, et al. Influence of anastrozole (Arimidex), a selective, non-steroidal aromatase inhibitor, on in vivo aromatisation and plasma oestrogen levels in postmenopausal women with breast cancer. Br J Cancer. 1996;74:1286-1291.

11. Geisler J, King N, Anker G, et al. In vivo inhibition of aromatization by exemestane, a novel irreversible aromatase inhibitor, in postmenopausal breast cancer patients. Clin Cancer Res. 1998;4:2089-2093.

12. Geisler J, Haynes B, Anker G, Dowsett M, Lonning PE. Influence of letrozole and anastrozole on total body aromatization and plasma estrogen levels in postmenopausal breast cancer patients evaluated in a randomized, cross-over study. J Clin Oncol. 2002;20:751-757.

13. Dowsett M, Jones A, Johnston SR, Jacobs S, Trunet P, Smith IE. In vivo measurement of aromatase inhibition by letrozole (CGS 20267) in postmenopausal patients with breast cancer. Clin Cancer Res. 1995; $1: 1511-1515$.

14. Burstein HJ, Griggs JJ, Prestrud AA, Temin S. American Society of Clinical Oncology clinical practice guidelines: update on adjuvant endocrine therapy for women with hormone receptor-positive breast cancer. J Clin Oncol. 2010;28:3784-3796.

15. Goldhirsch A, Ingle JN, Gelber RD, et al. Thresholds for therapies: highlights of the St Gallen International Expert Consensus on the Primary Therapy of Early Breast Cancer 2009. Ann Oncol. 2009;20:1319-1329.

16. Howell A, Cuzick J, Baum M, et al. Results of the ATAC (Arimidex, Tamoxifen, Alone or in Combination) trial after completion of 5 years' adjuvant treatment for breast cancer. Lancet. 2005;365:60-62.

17. Thürlimann B, Keshaviah A, Coates AS, et al. A comparison of letrozole and tamoxifen in postmenopausal women with early breast cancer. N Engl J Med. 2005;353:2747-2757.

18. Coates AS, Keshaviah A, Thürlimann B, et al. Five years of letrozole compared with tamoxifen as initial adjuvant therapy for postmenopausal women with endocrine-responsive early breast cancer: update of study BIG1-98. J Clin Oncol. 2007;25:486-492.

19. Mouridsen H, Giobbie-Hurder A, Goldhirsch A, et al. Letrozole therapy alone or in sequence with tamoxifen in women with breast cancer N Engl J Med. 2007;361:766-776.

20. Boccardo F, Rubagotti A, Puntoni M, et al. Switching to anastrozole versus continued tamoxifen treatment of early breast cancer: preliminary results of the Italian Tamoxifen Anastrozole Trial. J Clin Oncol. 2005;23:5138-5147

21. Coombes RC, Hall E, Gibson LJ, et al. A randomized trial of exemestane after two to three years of tamoxifen therapy in postmenopausal women with primary breast cancer. NEngl J Med. 2004;350:1081-1092. Erratum in: New Engl J Med. 2004;351:2461.

22. Coombes RC, Kilburn LS, Snowdon CF, et al. Survival and safety of exemestane versus tamoxifen after 2-3 years' tamoxifen treatment (Intergroup Exemestane Study): a randomised controlled trial. Lancet. 2007;369:559-570. Erratum in: Lancet. 2007;369:906.

23. Jones SE, Seynaeve C, Hasenburg A. Results of the first planned analysis of the TEAM (tamoxifen exemestane adjuvant multinational) prospective randomized phase III trial in hormone sensitive postmenopausal early breast cancer. Cancer Res. 2009;69 Suppl 2:67S Abstract 15 .
24. Chlebowski R, Cuzick J, Amakye D, et al. Clinical perspectives on the utility of aromatase inhibitors for the adjuvant treatment of breast cancer. Breast. 2009;18 Suppl 2:S1-S11.

25. Saphner T, Tormey DC, Gray R. Annual hazard rates of recurrence for breast cancer after primary therapy. J Clin Oncol. 1996;14: 2738-2746.

26. Mansell J, Monypenny IJ, Skene AI, et al. Patterns and predictors of early recurrence in postmenopausal women with estrogen receptor-positive early breast cancer. Breast Cancer Res Treat. 2009;117:91-98.

27. Lamerato L, Havstad S, Gandhi S, Jones D, Chlebowski R. Breast cancer recurrence and related mortality in US pts with early breast cancer. J Clin Oncol. 2005;23 Suppl 16:62S. Abstract 738.

28. Baum M, Buzdar A, Cuzick J, et al. Anastrozole alone or in combination with tamoxifen versus tamoxifen alone for adjuvant treatment of postmenopausal women with early-stage breast cancer: results of the ATAC (Arimidex, Tamoxifen Alone or in Combination) trial efficacy and safety update analyses. Cancer. 2003;98:1802-1810.

29. Goss PE, Ingle JN, Martino S, et al. Randomised trial of letrozole following tamoxifen as extended adjuvant therapy in receptor-positive breast cancer: updated findings from NCIC CTG MA.17. J Natl Cancer Inst. 2005;97:1262-1271.

30. Jakesz R, Jonat W, Gnant M, et al. Switching of postmenopausal women with endocrine-responsive early breast cancer to anastrozole after 2 years' adjuvant tamoxifen: combined results of ABCSG trial 8 and ARNO 95 trial. Lancet. 2005;366:455-462.

31. Forbes JF, Cuzick J, Buzdar A, et al. Effect of anastrozole and tamoxifen as adjuvant treatment for early-stage breast cancer: 100-month analysis of the ATAC trial. Lancet Oncol. 2008;9:45-53.

32. Jonat W, Hilpert F, Kaufmann M. Aromatase inhibitors: a safety comparison. Expert Opin Drug Saf. 2007;6:165-174.

33. Rea D, Hasenburg A, Seynaeve C, et al. Five years of exemestane as initial therapy compared to tamoxifen followed by exemestane for five years: the TEAM trial, a prospective, randomized, phase iii trial in postmenopausal women with hormone-sensitive early breast cancer. Cancer Res. 2009;69 Suppl:S24.

34. Hadji P, Aapro MS, Body JJ, et al. Practical guidance for the management of aromatase inhibitor-associated bone loss. Ann Oncol. 2008;19:1407-1416.

35. Clunie GP, Clark A, Mortimer CJ, et al. Evaluating bone health in women with oestrogen receptor positive breast cancer (ERBC) starting aromatase inhibitors. Eur J Surg Oncol. 2009;35:475-480.

36. Hadji P, Ziller M, Kieback DG, et al. Effects of exemestane and tamoxifen on bone health within the Tamoxifen Exemestane Adjuvant Multicentre (TEAM) trial: results of a German, 12-month, prospective, randomised substudy. Ann Oncol. 2009;20:1203-1209.

37. Delaney MF. Strategies for the prevention and treatment of osteoporosis during early postmenopause. Am J Obstet Gynecol. 2006;194 Suppl 2: S12-S23.

38. Gibson K, O'Bryant CL. Screening and management of osteoporosis in breast cancer patients on aromatase inhibitors. J Oncol Pharm Pract. 2008;14:139-145.

39. Gralow JR, Biermann JS, Farooki A, et al. NCCN Task Force Report: Bone Health in Cancer Care. J Natl Compr Canc Netw. 2009; 7 Suppl 3: S1-S32, S33-S35.

40. Geisler J, Lonning PE. Impact of aromatase inhibitors on bone health in breast cancer patients. J Steroid Biochem Mol Biol. 2010;118: 294-299.

41. Bertoldo F, Pancheri S, Zenari S, Boldini S. Emerging drugs for the management of cancer treatment induced bone loss. Expert Opin Emerg Drugs. 2010;15:323-342.

42. Yamamoto DS, Viale PH. Update on identifying and managing osteoporosis in women with breast cancer. Clin J Oncol Nurs. 2009;13: E18-E29.

43. Rugo HS. The breast cancer continuum in hormone-receptor-positive breast cancer in postmenopausal women: evolving management options focusing on aromatase inhibitors. Ann Oncol. 2008;19: 16-27. 
44. Eastell R, Hannon RA, Cuzick J, Clack G, Adams JE. Effect of anastrozole on bone density and bone turn over: results of the 'Arimidex' (anastrozole), Tamoxifen, Alone or in Combination (ATAC) study. J Bone Miner Res. 2002;17 Suppl 1:S165.

45. Gnant M, Hausmaninger H, Samonigg H. Changes in bone mineral density caused by anastrozole or tamoxifen in combination with goserelin (+/- zoledronate as adjuvant treatment for hormone receptor-positive premenopausal breast cancer: results of a randomized multicenter trial. Breast Cancer Res Treat. 2002;76 Suppl 1:S31. Abstract 12.

46. McCaig FM, Renshaw L, Williams L, et al. A randomised study of the effects of anastrozole (A), letrozole (L) and exemestane (E) on bone turnover. Breast Cancer Res Treat. 2009;119:643-651.

47. McCloskey E, Hannon R, Lakner G, Clack G, Miyamoto A, Eastell R. Interaction between body mass index and bone turnover during aromatase inhibition: evidence from the letrozole (L), exemestane (E), and anastrozole (A) pharmacodynamics (LEAP) trial. J Clin Oncol. 2007;25 Suppl 18:17S. Abstract 560.

48. Reid DM. Prevention of osteoporosis after breast cancer. Maturitas. 2009;64:4-8.

49. Coleman RE, Body JJ, Gralow JR, Lipton A. Bone loss in patients with breast cancer receiving aromatase inhibitors and associated treatment strategies. Cancer Treat Rev. 2008;34 Suppl 1:S31-S42.

50. Bundred NJ, Campbell ID, Davidson N, et al. Effective inhibition of aromatase inhibitor-associated bone loss by zoledronic acid in postmenopausal women with early breast cancer receiving adjuvant letrozole: ZO-FAST Study results. Cancer. 2008;112: $1001-1010$

51. Abdulhaq H, Geyer C. Safety of adjuvant endocrine therapy in postmenopausal women with breast cancer. Am J Clin Oncol. 2008;31:595-605.

52. Saad F, Adachi JD, Brown JP, et al. Cancer treatment-induced bone loss in breast and prostate cancer. J Clin Oncol. 2008;26:5465-5476.

53. Chapurlat RD, Bauer DC, Cummings SR. Association between endogenous hormones and sex hormone-binding globulin and bone turnover in older women: study of osteoporotic fractures. Bone. 2001;29:381-387.

54. Garnero P, Sornay-Rendu E, Claustrat B, Delmas PD. Biochemical markers of bone turnover, endogenous hormones and the risk of fractures in postmenopausal women: the OFELY study. J Bone Miner Res. 2000;15:1526-1536.

55. Rogers A, Saleh G, Hannon RA, Greenfield D, Eastell R. Circulating estradiol and osteoprotegerin as determinants of bone turnover and bone density in postmenopausal women. J Clin Endocrinol Metab. 2002;87:4470-4475.

56. Ettinger B, Pressman A, Sklarin P, Bauer DC, Cauley JA, Cummings SR. Associations between low levels of serum estradiol, bone density, and fractures among elderly women: the study of osteoporotic fractures. J Clin Endocrinol Metab. 1998;83:2239-2243.

57. Cummings SR, Browner WS, Bauer D, et al. Endogenous hormones and the risk of hip and vertebral fractures among older women. Study of Osteoporotic Fractures Research Group. $N$ Engl J Med. 1998;339:733-738.

58. Chapurlat RD, Garnero P, Breart G, Meunier PJ, Delmas PD. Serum estradiol and sex hormone-binding globulin and the risk of hip fracture in elderly women: the EPIDOS study. $J$ Bone Miner Res. 2000;15:1835-1841.

59. Perez EA. Safety profiles of tamoxifen and the aromatase inhibitors in adjuvant therapy of hormone-responsive early breast cancer. Ann Oncol. 2007;18 Suppl 8:viii26-viii35.

60. Eastell R, Hannon RA, Cuzick J, et al. Effect of an aromatase inhibitor on BMD and bone turnover markers: 2-year results of the Anastrozole, Tamoxifen, Alone or in Combination (ATAC) trial (182332030). J Bone Miner Res. 2006;21:1215-1223.

61. Berry J. Are all aromatase inhibitors the same? A review of controlled clinical trials in breast cancer. Clin Ther. 2005;27:1671-1684.
62. Rabaglio M, Sun Z, Price KN, et al. Bone fractures among postmenopausal patients with endocrine-responsive early breast cancer treated with 5 years of letrozole or tamoxifen in the BIG 1-98 trial. Ann Oncol. 2009;20:1489-1498.

63. Coleman RE, Banks LM, Girgis SI, et al. Skeletal effects of exemestane on bone-mineral density, bone biomarkers, and fracture incidence in postmenopausal women with early breast cancer participating in the Intergroup Exemestane Study (IES): a randomized controlled study. Lancet Oncol. 2007;8:119-127.

64. Hadji P, Ziller M, Kieback DG, et al. The effect of exemestane or tamoxifen on markers of bone turnover: results of a German sub-study of the Tamoxifen Exemestane Adjuvant Multicentre (TEAM) trial. Breast. 2009;18:159-164.

65. Pant S, Shapiro CL. Aromatase inhibitor-associated bone loss: clinical considerations. Drugs. 2008;68:2591-2600.

66. Yamamoto Y, Iwase H. Safety profiles of aromatase inhibitors and selective estrogen-receptor modulators in the treatment of early breast cancer. Int J Clin Oncol. 2008;13:384-394.

67. Hadji P, Aapro MS, Body JJ, et al. Management of aromatase inhibitor-associated bone loss in postmenopausal women with breast cancer: practical guidance for prevention and treatment. Ann Oncol. 2011;22:2546-2555.

68. Bundred NJ. Aromatase inhibitors and bone health. Curr Opin Obstet Gynecol. 2009;21:60-67.

69. Aapro M, Abrahamsson PA, Body JJ, et al. Guidance on the use of bisphosphonates in solid tumours: recommendations of an international expert panel. Ann Oncol. 2008;19:420-432.

70. Hadji P, Ziller M, Albert US, Kalder M. Assessment of fracture risk in women with breast cancer using current vs emerging guidelines. Br J Cancer. 2010;102:645-650.

71. Brufsky AM, Bosserman LD, Caradonna RR, et al. Zoledronic acid effectively prevents aromatase inhibitor-associated bone loss in postmenopausal women with early breast cancer receiving adjuvant letrozole: Z-FAST study 36-month follow-up results. Clin Breast Cancer. 2009;9:77-85.

72. Brufsky A, Harker WG, Beck JT, et al. The effect of zoledronic acid on aromatase inhibitor-associated bone loss in postmenopausal women with early breast cancer receiving adjuvant letrozole: the Z-FAST study 5-year final follow up. Presented at the 32nd Annual San Antonio Breast Cancer Symposium (SABCS), San Antonio, TX; December 9-13, 2009. Abstract 4083.

73. DeBoer R, Bundred N, Eidtmann H, et al. The effect of zoledronic acid on aromatase inhibitor associated bone loss in postmenopausal women with early breast cancer receiving adjuvant letrozole: the ZO-FAST study 5-year final follow-pp. Presented at the 33rd Annual San Antonio Breast Cancer Symposium (SABCS), San Antonio, TX; December 8-12, 2010. Abstract P5-11-01.

74. Coleman R, Gnant M. New results from the use of bisphosphonates in cancer patients. Curr Opin Support Palliat Care. 2009;3: 213-218.

75. Johnston SR, Dowsett M. Aromatase inhibitors for breast cancer: lessons from the laboratory. Nat Rev Cancer. 2003;3:821-831.

76. Gnant M, Clézardin P. Direct and indirect anticancer activity of bisphosphonates: a brief review of published literature. Cancer Treat Rev. October 7, 2011. [Epub ahead of print.]

77. Gnant M, Eidtmann H. The anti-tumour effect of bisphosphonates ABCSG-12, ZO-FAST and more... Crit Rev Oncol Hematol. 2010; 74 Suppl 1:S2-S6.

78. Cartenì G, Bordonaro R, Giotta F, et al. Efficacy and safety of zoledronic acid in patients with breast cancer metastatic to bone: a multicenter clinical trial. Oncologist. 2006;11:841-848.

79. Abraham J. Zoledronic acid improves disease-free survival in hormoneresponsive early breast cancer. Community Oncol. 2009;6:11-13.

80. Coleman RE, Marshall H, Cameron D, et al; AZURE Investigators. Breast-cancer adjuvant therapy with zoledronic acid. $N$ Engl J Med. 2011;365:1396-1405. 
81. Coleman R, Bundred N, de Boer R, et al. Impact of zoledronic acid in postmenopausal women with early breast cancer receiving adjuvant letrozole: Z-FAST, ZO-FAST, and E-ZO-FAST. Presented at the 32nd Annual San Antonio Breast Cancer Symposium (SABCS), San Antonio, TX; December 9-13, 2009. Abstract 4082.

82. Hines SL, Sloan JA, Atherton PJ, et al. Zoledronic acid for treatment of osteopenia and osteoporosis in women with primary breast cancer undergoing adjuvant aromatase inhibitor therapy. Breast. 2010; 19:92-96.

83. Nieves JW, Barrett-Connor E, Siris ES, et al. Calcium and vitamin $\mathrm{D}$ intake influence bone mass, but not short-term fracture risk, in Caucasian postmenopausal women from the National Osteoporosis Risk Assessment (NORA) study. Osteoporosis Int. 2008;19:673-679.

84. Boonen S, Lips P, Bouillon R, Bischoff-Ferrari HA, Vanderschueren D, Haentjens P. Need for additional calcium to reduce the risk of hip fracture with vitamin D supplementation: evidence from a comparative metaanalysis of randomized controlled trials. J Clin Endocrinol Metabol. 2007;92:1415-1423.
85. Jackson RD, LaCroix AZ, Gass M, et al. Calcium plus vitamin D supplementation and the risk of fractures. $N$ Engl J Med. 2006;354: 669-683. Erratum in: N Engl J Med. 2009;354:1102.

86. Kemmler W, Engelke K, von Stengel S, Weineck J, Lauber D, Kalender WA. Long-term four-year exercise has a positive effect on menopausal risk factors: the Erlangen Fitness Osteoporosis Prevention Study. J Strength Cond Res. 2007;21:232-239.

87. Lips P, Bouillon R, van Schoor NM, et al. Reducing fracture risk with calcium and vitamin D. Clin Endocrinol (Oxford). 2009;73:277-285.

88. Kanis JA. Diagnosis of osteoporosis. Osteoporosis Int. 1997;7 Suppl 3 S108-S116.

89. Shapiro CL, Manola J, Leboff M. Ovarian failure after adjuvant chemotherapy is associated with rapid bone loss in women with early-stage breast cancer. J Clin Oncol. 2001;19:3306-3311.

90. Powles TJ, Hickish T, Kanis JA, Tidy A, Ashley S. Effect of tamoxifen on bone mineral density measured by dual-energy x-ray absorptiometry in healthy premenopausal and postmenopausal women. J Clin Oncol. $1996 ; 14: 78-84$
Breast Cancer: Targets and Therapy

\section{Publish your work in this journal}

Breast Cancer: Targets and Therapy is an international, peerreviewed open access journal focusing on breast cancer research, identification of therapeutic targets and the optimal use of preventative and integrated treatment interventions to achieve improved outcomes, enhanced survival and quality of life for the cancer patient.

\section{Dovepress}

View the full aims and scopes of this journal here. The manuscript management system is completely online and includes a very quick and fair peer-review system, which is all easy to use. Visit http:// www.dovepress.com/testimonials.php to read real quotes from published authors

Submit your manuscript here: http://www.dovepress.com/breast-cancer---targets-and-therapy-journal 